\title{
HISTORIA NATURAL Y COSECHA DE CORTEZA DE QUINA AMARILLA HINTONIA LATIFLORA (RUBIACEAE)
}

\author{
Leonardo Beltrán-Rodríguez ${ }^{1}$, Angélica Romero-Manzanares ${ }^{1}$, Mario Luna-Cavazos ${ }^{1}$, Heike \\ Vibrans ${ }^{1}$, Fernando Manzo-Ramos ${ }^{1}$, Jesús Cuevas-SánChez ${ }^{2}$ y Edmundo García-Moya ${ }^{1,3}$ \\ ${ }^{1}$ Colegio de Postgraduados, Montecillo, Texcoco, Estado de México, México \\ ${ }^{2}$ Universidad Autónoma Chapingo, Texcoco, Estado de México, México \\ ${ }^{3}$ Autor para la correspondencia: edmundo@colpos.mx
}

\begin{abstract}
Resumen: Hintonia latiflora (Sessé \& Moc. ex DC.) Bullock, la "quina amarilla", es un árbol americano propio del bosque tropical caducifolio, valioso, debido a que la corteza tiene propiedades medicinales. La principal zona de abasto comercial de quina amarilla está al norte del estado de Guerrero, México. Esta contribución aporta información bibliográfica en torno a la historia natural y del aprovechamiento de $H$. latiflora en toda su área de distribución. Además, incorpora datos de campo originales acerca del hábitat, densidad, fenología, dispersión, arquitectura, comercialización e intensidad en el aprovechamiento de algunas poblaciones de quina amarilla de la cuenca alta del Río Balsas. Se encontraron factores biofísicos importantes para el establecimiento, crecimiento y supervivencia de la especie. La fenología consiste en la floración en la primavera-verano, foliación en el verano, fructificación a finales del verano y dispersión durante el invierno. La dispersión es anemócora y barócora. La arquitectura arbórea se relaciona con factores ambientales y la cosecha de corteza. Se observó que la densidad y disponibilidad de la especie cambian con las características de los sitios y con la intensidad de recolección. La comercialización de la quina implica a tres actores: los recolectores, los acopiadores locales y los compradores regionales. Los precios históricos de la corteza al consumidor han aumentado pero al considerar los precios sin inflación, realmente han bajado. Se destaca que la mayor amenaza para las poblaciones es la intensidad de aprovechamiento y la práctica descuidada de la cosecha.
\end{abstract}

Palabras clave: arquitectura vegetal, comercialización, etnobotánica, fenología, recolección.

\begin{abstract}
Hintonia latiflora (Sessé \& Moc. ex DC.) Bullock, the "quina amarilla", is an American tree of the tropical deciduous forest which is valuable because its bark has medicinal properties. The main area supplying the commercial quina amarilla is the northern of Guerrero state, Mexico. This contribution reports bibliographic information pertaining to the natural history and harvesting in its whole distribution area. Also, it includes field data on the habitat, density, phenology, dispersal, architecture, harvest intensity, and commercialization in some populations from the upper Rio Balsas Basin. The results shows biophysical factors that are important for growth, establishment, and survival of the species. Phenology consists of flowering in spring-summer, foliation in summer, fruiting in late summer, and dispersal in winter. The dispersal is anemocorous and barocorous. Tree architecture is related to environmental factors and to bark harvesting. Density and availability of the species changes with site characteristics and the intensity of the harvesting. The commercialization involves three actors: gatherers, local middlemen, and regional traders. The historical prices of the bark to the consumers have increased, but considering inflation, really have decreased. The major threat to the populations of $H$. latiflora is harvesting intensity and careless practice of harvesting.
\end{abstract}

Key words: commercialization, ethnobotany, harvesting, phenology, plant architecture.

$\mathbf{E}$ género Hintonia agrupa a tres especies distribuidas principalmente en las regiones tropicales y subtropicales de América (Delprete, 2004). La especie tipo es Hintonia latiflora (Sessé \& Moc. ex DC.) Bullock, que se encuentra del noroeste de México a Centroamérica; las otras son H. lunana (Baillon) Bullock, del sureste de México y Centroamérica, y H. octomera (Hemsley) Bullock, endémica de la Península de Yucatán y Guatemala. Las tres especies convergen en Guatemala; son árboles no mayores a $10 \mathrm{~m}$ de altura y habitan en los bosques tropicales caducifolios, perennifolios y dunas costeras.

Hintonia latiflora ha sufrido confusión en su taxonomía (Ochoterena-Booth, 2000) y etnobotánica (Mata et al., 2009). En este último caso ha sido porque forma parte de un 
grupo de especies que, en México, tienen el mismo nombre común: quina, y que se asemejan en las características morfológicas, aromáticas y de uso medicinal de sus cortezas. Existe un conjunto de 26 especies de diferentes familias que conforma el "Complejo Quina” (Anaya-Dávila Garibi, 1991), el cual ha sido subdividido en dos grupos: quina roja y quina amarilla, por el color de sus cortezas internas. H. latiflora es del grupo quina amarilla y es la única especie del género Hintonia con uso medicinal, importancia económica y comercial en México; sus propiedades medicinales han sido objeto de múltiples estudios fitoquímicos (Mata et al., 2009).

Se desconocen numerosos aspectos de la biología y ecología de Hintonia latiflora y la información disponible se encuentra dispersa, a menudo en el formato de tesis, bases de datos y otra literatura poco accesible. Entonces, los objetivos de esta contribución fueron, con base en la literatura existente, documentar, analizar y discutir la información sobre la historia natural y de cosecha de H. latiflora en su área de distribución. Adicionalmente, se aporta información obtenida en campo acerca de la arquitectura y fenología de la planta, atributos ecológicos, dispersión, recolecta y comercialización.

\section{Materiales y métodos}

Área de estudio. Este trabajo se hizo en Tlalcozotitlán-Copalillo, estado de Guerrero, localizado en la Cuenca Alta del Balsas, a $17^{\circ} 52^{\prime} 58^{\prime \prime} \mathrm{N}, 99^{\circ} 07^{\prime} 48^{\prime \prime} \mathrm{O}$, entre altitudes de 560 a $1,580 \mathrm{~m}$. El bosque tropical caducifolio domina la zona, presenta disturbio en áreas cercanas a Tlalcozotitlán y está más conservado hacia sitios distantes. La población se dedica a la agricultura de temporal y ribereña, complementada con la recolección de resina de copal, plantas medicinales, leña y materiales para artesanías. Tlalcozotitlán es parte de la región de abasto de quinas amarillas para el centro del país, especialmente de Hintonia latiflora (Beltrán-Rodríguez, 2013).

Revisión de literatura. Se hizo la revisión de la literatura disponible o referenciada en varias bases y buscadores de datos nacionales e internacionales. Además, se consultaron tesis de la Universidad Nacional Autónoma de México, del Instituto Politécnico Nacional, de la Universidad Autónoma del Estado de Morelos, de la Universidad Autónoma Chapingo y del Colegio de Postgraduados. Para la distribución geográfica de Hintonia latiflora se consultó la Red Mundial de Información sobre Biodiversidad (REMIB), la Unidad de Informática para la Biodiversidad (UNIBIO), la base Tropicos del Missouri Botanical Garden (http://www.tropicos. org) y literatura especializada (floras, listados, monografías y revisiones). Para validar colectas citadas por fuentes bibliográficas y verificar detalles de ejemplares de los repositorios, se consultó el Herbario Nacional de México (MEXU), el Herbario de la Universidad Autónoma del Esta- do de Morelos (HUMO) y el Herbario Hortorio del Colegio de Postgraduados (CHAPA).

Trabajo de campo. Consistió en recabar información en torno a la historia natural y de cosecha de la planta durante 2012. Se incluyeron arquitectura arbórea, fenología, biología reproductiva y características ecológicas, su relación con factores del medio e influencia de la práctica de recolección.

Muestreo. Se seleccionaron ocho sitios de muestreo mediante mapeos participativos con recolectores en zonas de aprovechamiento. Cuatro de los sitios tenían una dirección $\mathrm{N}-\mathrm{S}$ y cuatro disposición E-O. Para el estudio poblacional se marcaron tres transectos de $20 \times 100 \mathrm{~m}$ en cada uno de los ocho sitios, lo que resultó en un total de 4.8 ha de superficie muestreada. Dentro de los transectos se establecieron parcelas de $6 \mathrm{~m}^{2}$ bajo y fuera de dosel arbóreo para la cuantificación de plántulas. Las plantas juveniles se registraron en 96 unidades de muestreo de $8 \times 20 \mathrm{~m}$, mientras que para los árboles adultos se trabajaron en 24 unidades de muestreo de $10 \times 100 \mathrm{~m}$.

Observaciones de población. El estudio fenológico se hizo mediante visitas mensuales en 117 individuos adultos, encontrados y marcados durante el muestreo de campo. Se estimaron porcentajes de foliación, floración, fructificación y dispersión. Con los datos se elaboró el calendario fenológico de la especie; también se hicieron observaciones del tiempo de maduración de las estructuras femeninas y masculinas de las flores, y la posibilidad de heterostilia (característica citada por Ochoterena-Booth, 2000). Se obtuvo la densidad promedio y el valor de importancia (IVI) de adultos y juveniles de Hintonia latiflora. El estadio de desarrollo de los individuos fue determinado por relaciones alométricas. Se consideraron juveniles aquellos individuos con altura entre 0.1 y $3 \mathrm{~m}$, con diámetro basal de 0.6 a $8 \mathrm{~cm}$, sin evidencia de estructuras reproductivas. Los adultos tenían una altura de 3.1 a $8 \mathrm{~m}$ y diámetro de 8.1 a $20 \mathrm{~cm}$, con estructuras reproductivas confirmadas.

Arquitectura arbórea. El modelo arquitectónico fue determinado para las etapas juveniles y adultas. Para ello se consideraron la forma de crecimiento del eje principal (monopodial, simpodial), la forma de ramificación (basal, media, apical), la posición de las ramas (dorsiventral, helicoidal), el número de ramas, y la posición de las estructuras vegetativas y reproductivas (axilar, apical), de acuerdo con los criterios de Hallé et al. (1978) y Hallé (2010). Las mediciones dasométricas incluyeron: altura total, diámetro basal (DB), ángulo de ramificación con respecto al suelo, longitud de los diferentes órdenes de ramificación a partir de la primera bifurcación, ángulo de inserción de los órdenes de ramificación y número de frutos por rama. Se discuten las variantes 
del modelo arquitectónico y el hábitat, así como el hábito de crecimiento en relación con el aprovechamiento.

Recolecta y comercialización. Se realizaron entrevistas estructuradas y se acompañó al campo a 12 recolectores, que representan el 60\% del total de recolectores en Tlalcozotitlán, para conocer el método de extracción de corteza. Para estimar la cantidad de cosecha, se descortezó totalmente un árbol adulto de $3.20 \mathrm{~m}$ de altura, $4.60 \mathrm{~m}$ de cobertura y 39 $\mathrm{cm}$ de diámetro basal; el material recolectado se procesó a peso seco. La tendencia en el precio de la corteza de quina amarilla se obtuvo de los costos de venta a los consumidores referidos por Hersch-Martínez en 1989 (Hersch-Martínez, 1996), Anaya-Dávila Garibi (1991) y Bye et al. (2000), y del precio de venta para abril del 2011 en el principal mercado de plantas medicinales en la ciudad de México, el Mercado de Sonora. El cálculo de los precios reales se hizo con datos de inflación de diciembre 2011, con la calculadora de la página del INEGI (www.inegi.org.mx).

\section{Resultados}

Revisión bibliográfica. Ochoterena-Booth (2000) narra que a partir de una ilustración obtenida de la expedición de Sessé y Mociño, la quina amarilla fue identificada erróneamente como Portlandia hexandra Jacq. Luego, a la misma, A. de Candolle en 1830 la equiparó como Coutarea latiflora DC., y más tarde, Bullock (1935) estableció el género y la circunscripción del género Hintonia actual, resultando sinónimo de Portlandia. Este autor separó a la especie Hintonia latiflora en dos variedades: $H$. latiflora var. latiflora Bullock y $H$. latiflora var. leiantha Bullock, debido a las diferencias en el color de la corola, la forma de la cápsula y la longitud de las flores, considerando a Portlandia pterosperma S.Watson como sinónimo de H. latiflora var. latiflora. Borhidi (2006) no reconoce a la variedad leiantha y sí considera a $H$. standleyana como una especie distinta; añade la pubescencia del cáliz y de las hojas como características diferenciales. Resalta el desconocimiento del número cromosómico básico de H. latiflora (Kiehn, 1995), pero existen algunas evidencias moleculares que apoyan la separación de las especies (Stranczinger et al., 2006), como son las secuencias de ADN de H. latiflora con diferentes números de acceso en el GenBank (Manss y Bremer, 2010).

Nombres comunes. En México se conocen 41 nombres populares para Hintonia latiflora. Los más frecuentes son: cáscara sagrada, copalchi, copalquin, palo amargo, quina y quina amarilla (Anaya-Dávila Garibi, 1991; BDMTM, 2009). Se desconocen los nombres vernáculos para la especie en los países de Centroamérica (Ocampo, 1994).

Descripción botánica. Esta sección se integra parcialmente, por las descripciones de Ochoterena-Booth (2000), Borhidi
(2006) y Castañeda-Huitrón (2010). Los datos de semilla se obtuvieron de Hernández-Pérez (2006), Soriano et al. (2011) y la Seed Information Database (2013). Hintonia latiflora es un árbol o arbusto de hasta $10 \mathrm{~m}$ de altura, con ramas pilosas o glabras; estípulas deltoides caducifolias, ligeramente fusionadas por encima del peciolo. Hojas decusadas, peciolo glabro o pubescente, lámina foliar elíptica a circular, 1.5 a $12 \mathrm{~cm}$ de largo, base simétrica y ápice acuminado o agudo. Color verde oscuro en el haz y verde claro por el envés. Ambas superficies son pubescentes, más blanquecina en el envés, con depósitos de cera sobre la vena principal; los domacios están ausentes o son escasos. Las flores son hexámeras, axilares, solitarias y hermafroditas, fragantes, de 5 a $7 \mathrm{~cm}$ de longitud. El pedicelo puede tener un par de bractéolas no conectadas por estípulas; los lóbulos del cáliz son verdoso-amarillentos, lineares, estrechamente triangulares o raramente frondosos, expandidos o involutos. El tubo de la corola es de color blanco cremoso en antesis, infundibuliforme; las anteras tienen dehiscencia latrorsa, con arreglo paralelo de las tecas, glabras o pubescentes. El polen es esférico, difusamente foveolado. El ovario es ínfero con heterostilia (estilo filiforme más corto o largo) que los estambres, con el estigma entero o ligeramente bilobado. El óvulo es anátropo; el embrión es axial-espatulado y blanco, sin perispermo. La cápsula es septicida, bilocular, subcilíndrica a subesférica, ligeramente comprimida, $1.5-3.5 \mathrm{~cm}$ de largo, 1.2-1.8 cm de ancho, con seis o ninguna costilla, con o sin lenticelas. Las semillas tienen forma ovalada, color amarillo claro, de 0.5-0.8 cm de largo y $0.3-0.5 \mathrm{~cm}$ de ancho, son aladas, de testa reticulada y sin sarcotesta. La semilla se haya comprimida lateralmente e imbricada en el ovario, con la superficie áspera, rafe e hilo pequeño. El peso promedio por semilla es de $2.16 \mathrm{~g}$. El cotiledón es fanerocotilar, epígeo y fotosintético.

La figura 1 y la 4 (relacionada con arquitectura), muestran caracteres de la planta no descritos en la literatura y aportados por esta investigación, sobre la presencia y disposición del súber en tallo y ramas proximales. El ritidoma mide $1.7 \mathrm{~cm}$ de grosor en la base del tronco, acumulado en disposición helicoidal por el lado soleado del tallo o hacia la orientación sur, y también se le ve en las ramas proximales (Figura1A); el tipo de ramificación es dicotómica cerca de la unión con el tallo, pero simpodial a la vista (Figura 1B) porque una rama engrosa más que la otra y forma un eje zig-zagueante órdenes más arriba. Nótese que no necesariamente se forma un tronco (Figura 4F), y que todas las ramas dicotómicas emergen desde la base, lo que crea la imagen de un arbusto pequeño, frondoso y multirramificado. En las formas arbóreas monopódicas, a partir del primer orden de ramificación y del lado opuesto al acúmulo de ritidoma, la corteza externa es ligeramente lisa, firmemente adherida y tiene un grosor menor que $0.5 \mathrm{~cm}$. Del lado que no desarrolla ritidoma hay abundantes lenticelas de $2 \mathrm{~mm}$, a veces dispuestas en hileras longitudinales. La corteza interna recién 


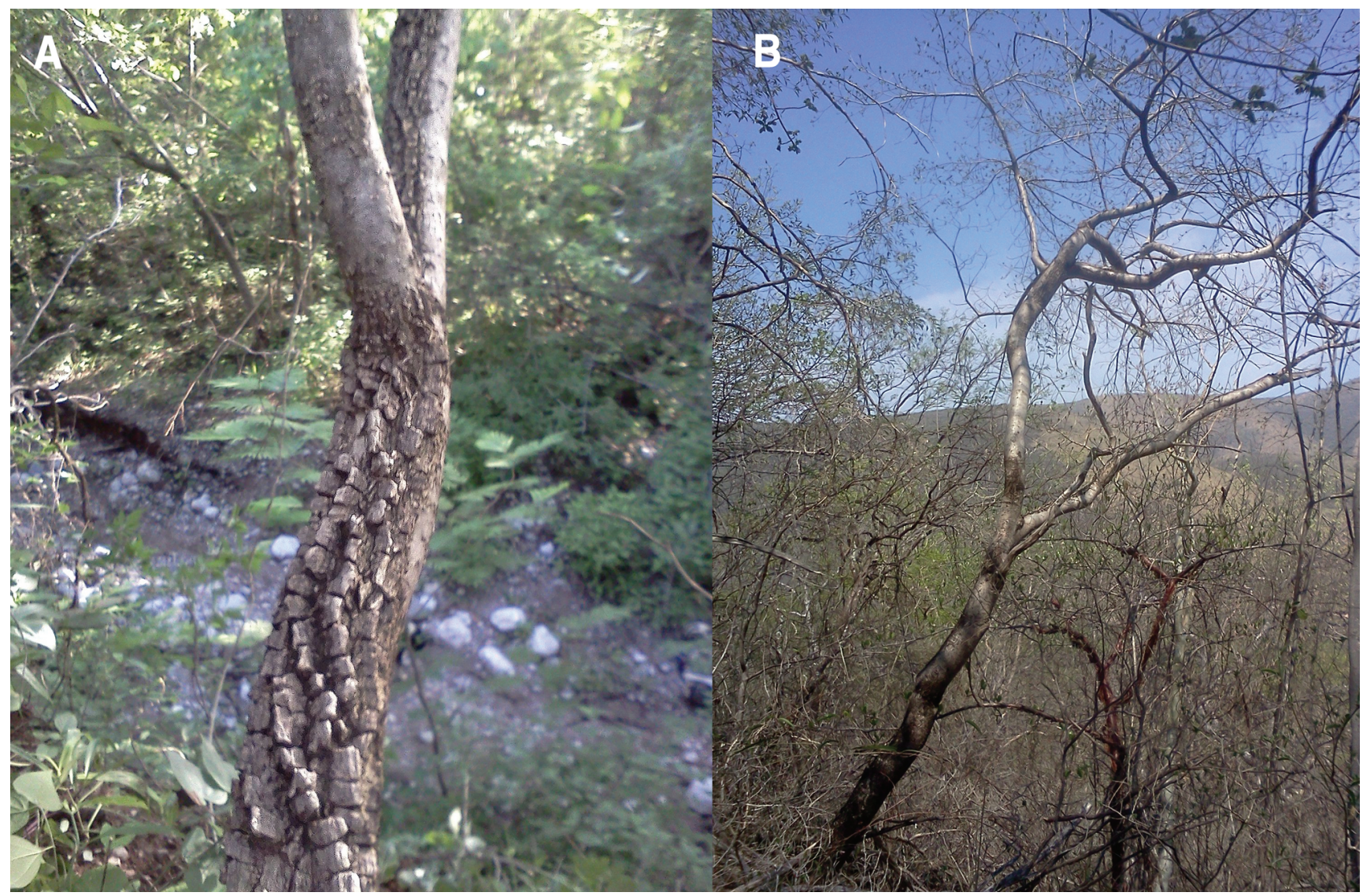

Figura 1. Hintonia latiflora: A) Aspecto de la corteza externa. El ritidoma corchoso se dispone en franjas helicoidales. B) Ramificación dicotómica que por el mayor desarrollo de una rama aparenta ser simpódica en las ramas proximales al tallo y netamente dicotómica en las más distales.

cortada es amarillenta y se torna anaranjada hasta negra al contacto con el aire. En la forma arbustiva el ritidoma no es evidente.

Distribución geográfica. Los registros de herbario indican que en México, Hintonia latiflora se distribuye en diferentes provincias biogeográficas, con una presencia notable en la Depresión del Balsas, la Costa del Pacífico y la Sierra Madre del Sur. También es frecuente en las costas de Sonora, la Sierra Madre Occidental, y alcanza su límite sur en Chiapas y más allá de la frontera Mexicana, hasta Guatemala y El Salvador (Figura 2).

Hábitat. El hábitat de Hintonia latiflora corresponde con los bosques tropicales caducifolios, subcaducifolios y matorrales xerófilos (Standley y Williams, 1975; Lorence y Taylor, 2012), en cualquier estadio serial, desde inicial hasta tardío (Romero-Duque et al., 2007; Monroy-Ortiz et al., 2013). La especie crece sobre material parental ígneo o granítico, sedimentario, en suelos arcillosos y limosos, de color negro, rojo o amarillo-rojizo; en altitudes que varían entre 10 y 2,200 m snm (López et al., 2011). En Chamela, Jalisco, la quina vive sobre suelos con textura arenosa, principalmente en los de alto intercambio de iones y de $\mathrm{MgO}$ (Vargas-Rodríguez et al., 2005). En cuanto a la interacción de H. latiflora con la biofísica del suelo, se ha mencionado que la simbiosis micorrizógena aporta minerales adquiridos por el hongo para favorecer características del desarrollo, como velocidad de crecimiento, altura y tasa de producción de hojas y ramas en el dosel

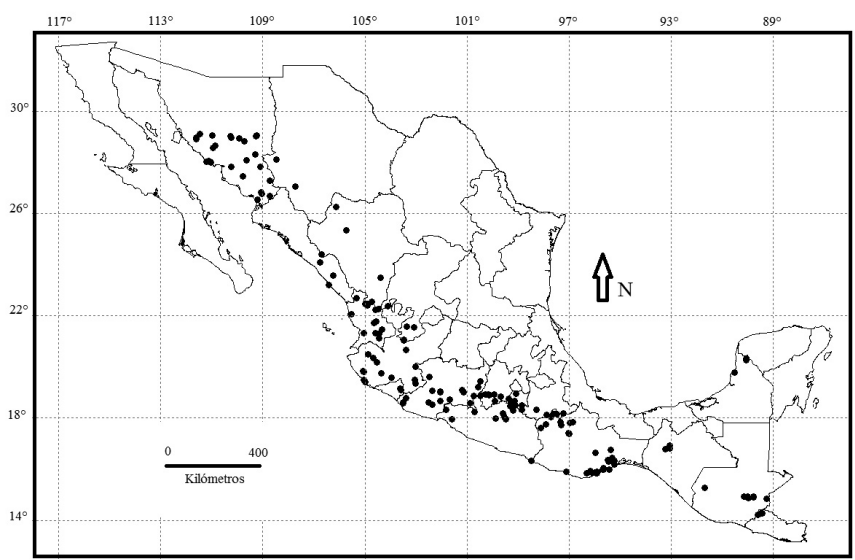

Figura 2. Distribución de Hintonia latiflora en México y Centroamérica. Mapa elaborado con registros de herbario. 


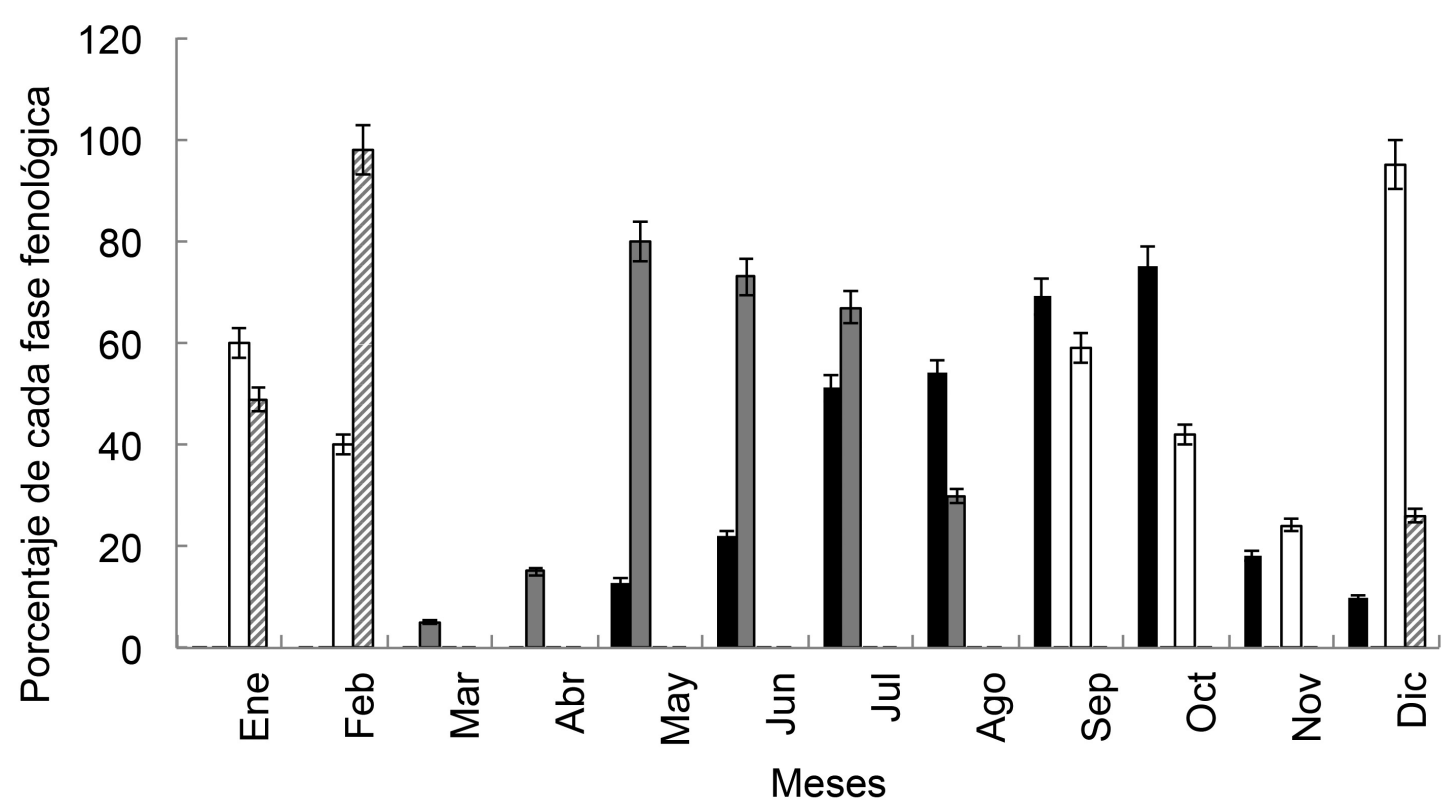

Figura 3. Fenología de Hintonia latiflora en Tlalcozotitlán, Guerrero, México, datos de campo, 2012. Porcentaje ( \pm EE) calculado a partir del número de individuos en cada fase fenológica $(n=117)$. Foliación (negro), floración (gris), fructificación (blanco) y dispersión de semillas (achurado).

de plantas juveniles y adultas (Huante et al., 2012), pero, en opinión de Gavito et al. (2008), la asociación con hongos micorrizógenos arbusculares no limita el establecimiento y desarrollo de plántulas. Se menciona que la quina no incrementa biomasa al fertilizarla con nitrógeno (Lawrence, 2003).

Fenología. Las plantas de Hintonia latiflora en Tlalcozotitlán, primero florecen y después folian las ramas. La floración masculina temprana inicia en marzo, el óptimo se presenta en la primera semana de abril y la fase tardía ocurre hasta la primera semana de junio; la fase femenina comienza a mediados de abril, alcanza su óptimo en la tercera semana de mayo y concluye a finales de junio. Estos datos sugieren que la mayor probabilidad de fertilización está entre la segunda semana de abril y la tercera semana de mayo. Los frutos comienzan a desarrollarse hacia la primera semana de septiembre (Figura 3).

Biología floral. Los detalles estructurales de la flor ya fueron referidos en párrafos previos, pero quedaba en duda la heterostilia y la confirmación de la protandria. Ejemplares en el Herbario CHAPA, así como las colectas en el área de estudio, muestran que los estambres y el estigma coinciden en posición, por lo que se rechaza la sospecha de heterostilia. Se confirma que las flores son protándricas. La polinización de la flor es mediada por lepidópteros nocturnos y quirópteros (Motley et al., 2005).

Dispersión. La cápsula se abre en dos etapas: en la primera se separa la doble pared del septo, sin liberar las semillas y, en la segunda que no siempre ocurre, se divide la pared del septo a lo largo de la línea media de dehiscencia para liberar a las semillas anemócoras (Aiello, 1979; Motley et al., 2005; Arredondo-Amezcua, 2010). Se observó en Tlalcozotitlán, que algunos frutos maduran y caen bajo el dosel de la planta madre sin liberar a las semillas; esto es, la dispersión es barócora. Entonces, Hintonia latiflora utiliza una combinación de anemocoria y barocoria, lo que origina dispersión aleatoria y a gran distancia, pero también, diseminación en masa bajo la planta madre.

Germinación. La reserva contenida en las semillas se compone de 19.8-25.5\% de lípidos, 3.4-3.7\% de nitrógeno y 60.0-60.2\% de carbohidratos no estructurales (Soriano et al., 2011). Las semillas de Hintonia latiflora son ortodoxas, viables y germinables al $100 \%$ en laboratorio, a temperaturas de 15,20 y $25^{\circ} \mathrm{C}$ (Seed Information Database, 2013). Fierro et al. (2000) obtuvieron menor germinación, 72 a $83 \%$ en laboratorio, con aplicación de ácido giberélico (50 ppm) en inmersión de 12 horas. En otro experimento con fotoperiodo de 12 horas y 25 a $30^{\circ} \mathrm{C}$, la germinación fue de 57 y $68 \%$, con tiempo de inicio de cuatro días (HernándezPérez, 2006; Soriano et al., 2011). Se carece de información en cuanto a la germinación en campo.

Propagación vegetativa. Hintonia latiflora no tiene estructuras de propagación vegetativa. El interés por cultivar a la especie ha llevado a experimentar con la siembra de entrenudos como explantes (Castañeda-Huitrón, 2010), lo que genera un bajo número de brotes y de enraizamiento $(<$ $1 \%$ ); en vivero se ha logrado $7 \%$ de enraizamiento de estacas (Fierro et al., 2000). 

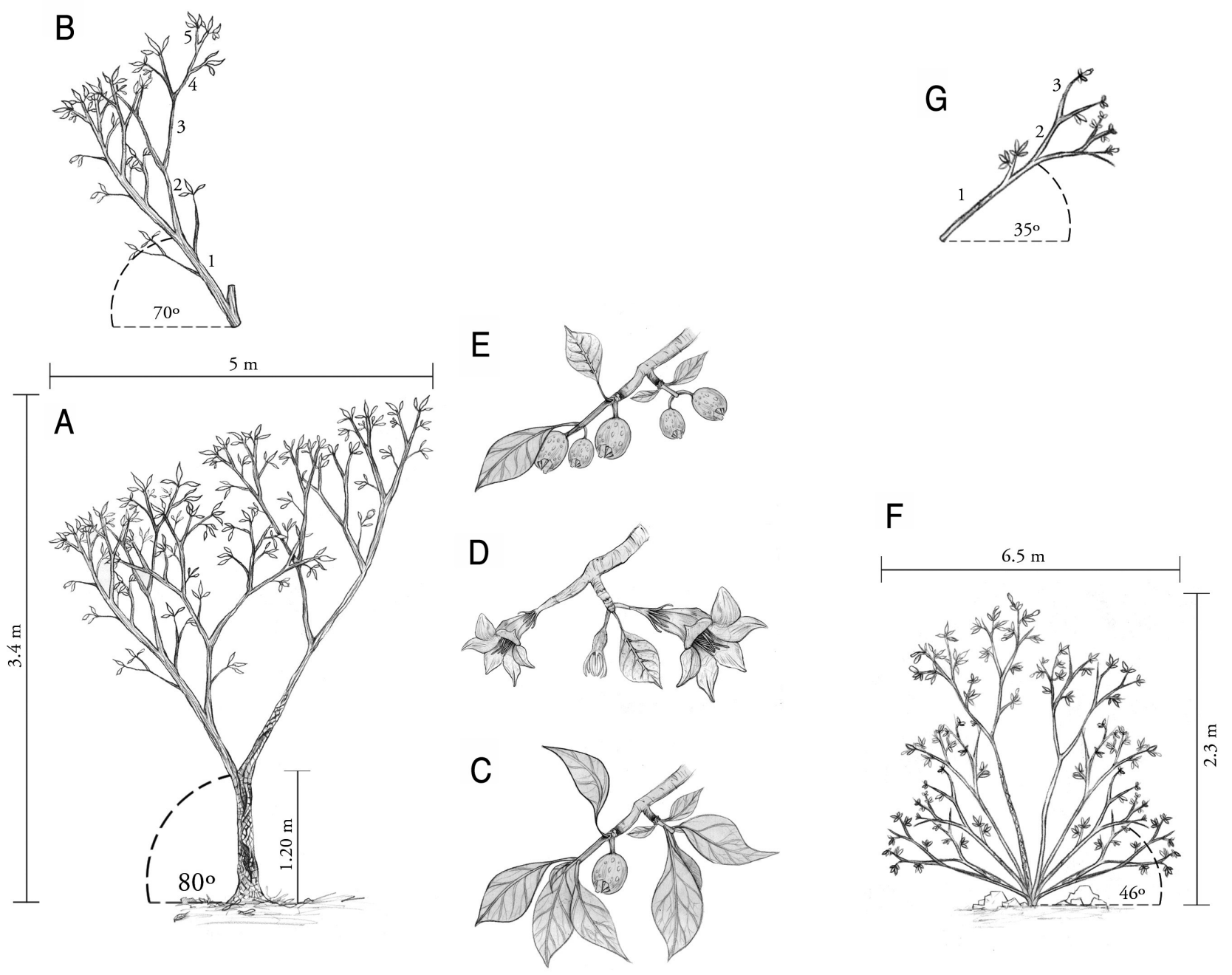

Figura 4. Arquitectura de Hintonia latiflora, según el modelo Leeuwenberg. A) morfotipo arbóreo, indica ángulo de inclinación con respecto al suelo, altura y cobertura; B) órdenes de ramificación en árbol, ángulo con respecto al eje principal, patrón de ramificación bifurcado; C) hojas con filotaxia decusada; D) flores solitarias y apicales; E) frutos apicales; F) morfotipo adulto arbustivo-multirramificado, ángulo de inclinación con respecto al suelo, altura y cobertura; y G) órdenes y ángulos de ramificación del ejemplar arbustivo. Se observa crecimiento dicotómico.

Defensa y principios activos. El valor de la corteza de Hintonia latiflora se deriva de sus principios activos (Mata et al., 2009). La corteza contiene aceite fijo, caucho, resinas, materia colorante, taninos, principios amargos, alcaloides (ácido desoxicordifolínico), cucurbitacinas (cuatro derivados de dihidrocucurbitacina F), flavonoides, fenilcumarinas (4-fenilcumarinas y 4-fenil-5,2'-óxido-cumarinas) y glucocucurbitacinas (Camacho, 1990; Argotte-Ramos et al., 2006; Cristians et al., 2009). La fenilcumarina y glucocucurbitacina han sido ingredientes activos validados clínicamente contra el paludismo (Mata et al., 2009). Su efecto antidiabético, anticancerígeno, antimalárico y gastroprotectivo también ha sido corroborado (Alonso-Castro et al., 2011; Cristians et al., 2013); al igual que los efectos secundarios a su consumo, identificados como ataxia (falta de coordinación de movimientos) e hiperactividad (Déciga-Campos et al., 2007). Los compuestos secundarios que fungen como defensas químicas en $H$. latiflora son alelopáticos, fungicidas y sabores desagradables para herbívoros (Harborne, 1993; Gross, 2008).

Densidad. La densidad en estadio juvenil y adulto de Hintonia latiflora para diferentes regiones de México es baja (Cuadro 1). En Tlalcozotitlán se encontraron, en promedio, 21 plántulas por $\mathrm{m}^{2}$ bajo la planta madre, mientras que en sitios desprotegidos o bajo el dosel de Lysiloma acapulcense (Kunth) Benth. y Conzattia multiflora (B.L.Rob.) Standl., se registró una densidad de 10 plantas ha ${ }^{-1}$. Fueron observadas mas no cuantificadas, plántulas sobre suelos ricos en materia orgánica, frecuentemente asociadas a Bursera simaruba (L.) Sarg. y Pseudobombax ellipticum (Kunth) Dugand. El IVI para juveniles y adultos se muestra en el mismo cuadro.

Arquitectura arbórea y arbustiva. Hintonia latiflora es principalmente una planta de hábito arbóreo y fuste monopó- 
dico (Figura 4A); en sitios húmedos y sombreados alcanza $3.4 \pm 0.6 \mathrm{~m}$ en individuos adultos y $1.9 \pm 0.9 \mathrm{~m}$ de altura en individuos juveniles; el dosel es extenso, tiene un diámetro de copa de hasta $5 \mathrm{~m}$. El patrón de ramificación alcanza hasta quinto orden (Figura 4B). El tallo mide $1.20 \pm 0.15$ $\mathrm{m}$ de longitud del suelo al inicio de la ramificación. Tiene un crecimiento dicotómico, con ángulo promedio de inclinación de $80^{\circ}$ en relación con el suelo, $10^{\circ}$ con respecto al tallo; es determinado, ya que el ápice vegetativo es sustituido por estructuras reproductivas, y proléptico, es decir, de crecimiento rítmico. Las ramas de primero a quinto orden en relación con el eje principal, están verticalmente orientadas, son ortotrópicas, y la longitud promedio de una rama de primer orden es de un $1 \pm 0.60 \mathrm{~m}$. Las hojas son ovadas y ahusadas, y tienen filotaxia decusada. Las flores son solitarias y apicales. Los frutos son cápsulas, en promedio se producen $107 \pm 33$ por rama (Figura 4C, D, E). El patrón arquitectónico básico es Leeuwenberg.

Cuando Hintonia latiflora se desarrolla en sitios abiertos, soleados y deteriorados, las plantas crecen como arbustos multirramificados (Figura 4F), con hasta nueve ramas procedentes de la base del tallo en individuos adultos y hasta seis en juveniles, que alcanzan $2.3 \pm 1.5 \mathrm{~m}$ promedio de altura en individuos adultos $\mathrm{y}, 1.4 \pm 0.9 \mathrm{~m}$ promedio en juveniles, con un dosel de hasta $6.5 \mathrm{~m}$. El patrón de ramificación es bifurcado (Figura 4G); las ramas basales, ramifican a alturas de entre 80 y $90 \mathrm{~cm}$, con un ángulo de inclinación de $46^{\circ}$ con relación al suelo, lo que hace al dosel más extenso. Tiene ramas multiestratificadas, con ejes ortotrópicos y en algunos casos plagiotrópicos, y con filotaxia decusada. El patrón de ramificación en arbustivas, la presencia y localización de hojas, flores y frutos (Figura 4C, D, E), es semejante al patrón de crecimiento arbóreo. La producción de frutos es menor en el morfotipo arbustivo multirramificado, con $80 \pm 7$ frutos por rama.

\section{Aprovechamiento e historia de la comercialización.}

Historia del uso de Hintonia latiflora.- Al concluir las expediciones botánicas en la Nueva España, a cargo de Sessé,
Castillo y Mociño, este último enlista una serie de plantas que considera fundamentales para conformar la Materia Médica Nacional. Él se refirió a dos copalchis (dos especies con el mismo nombre común), uno de ellos era de Guadalajara, Jalisco, determinado como Portlandia hexandra, ahora Hintonia latiflora, y otro de Tehuantepec, Oaxaca (Croton febrifugum Jacq.). El efecto febrífugo de estos copalchis llegó a compararse con el de la quina peruana, Cinchona, otra Rubiaceae. De ahí fue que se utilizó de manera indistinta los nombres quina y copalchi para plantas pertenecientes a las familias Rubiaceae y Euphorbiaceae, por lo que su uso y comercialización ha estado acompañado de sustituciones, confusiones y adulteraciones.

Actualmente la corteza de Hintonia latiflora tiene 36 diferentes usos en México, los más populares son como antidiabético y febrífugo (Anaya-Dávila Garibi, 1991; BDMTM, 2009). Hersch-Martínez (2007) relata acerca de una empresa mexicana pionera en producir medicina a base de corteza de H. latiflora, como la glucolisina y el extracto fluido de copalchi, allá por los años 1920. Destaca que por desventaja industrial, México se dedicó a exportar la corteza e importar extractos medicinales de Alemania; en Europa todavía se venden remedios basados en $\mathrm{H}$. latiflora, el Copalchi Novellas en España, la Tisane Copaltra en Francia y el Sucontral en Alemania, supuestamente de quina amarilla mexicana.

Recolecta y comercialización.- En Tlalcozotitlán existen tres formas de recolecta de la corteza. El 90\% de los recolectores retiran toda la corteza del individuo, tanto del tallo como de las ramas, ya sea de la planta en pie o derribada, lo que ocasiona la muerte del árbol (Figura 5). Otros, cosechan de tal manera que afectan la corteza interna, lo que también causa la muerte de la planta. Solo un recolector cosecha dos secciones longitudinales del tallo, dejando el resto con la finalidad de que el árbol se recupere.

El cuadro 2 muestra la producción de corcho según la etapa de desarrollo de los árboles. Los árboles producen mayor volumen de corteza debido a que tienen más ramas, tallo

Cuadro 1. Densidad y valor de importancia de Hintonia latiflora en México. *El valor de importancia para la comunidad de Tlalcozotitlán fue estimado con base en la composición florística total. Esos datos no están expuestos en el presente documento.

\begin{tabular}{|c|c|c|c|c|c|}
\hline Área de estudio & Promedio (ind. ha-1) & Valor de importancia & Uso de la tierra & Método de muestreo & Autor \\
\hline Sonora & Dos & $0.6-1.7$ & $\begin{array}{l}\text { Ganadero de alta } \\
\text { intensidad }\end{array}$ & Transecto & $\begin{array}{l}\text { Álvarez-Yépiz } \\
\text { et al., } 2008\end{array}$ \\
\hline Jalisco & $\begin{array}{l}\text { Dos adultos y } \\
\text { uno juvenil }\end{array}$ & $\begin{array}{c}2.3 \text { en plántulas y } \\
\text { juveniles - } 28 \text { en adultos }\end{array}$ & $\begin{array}{l}\text { Reserva de la Biósfera } \\
\text { Sierra de Manantlán }\end{array}$ & Transecto & $\begin{array}{l}\text { Vargas-Rodríguez } \\
\text { et al., } 2005\end{array}$ \\
\hline Morelos & Cuatro & 7.4 & $\begin{array}{c}\text { Reserva Estatal } \\
\text { Montenegro, Morelos. }\end{array}$ & Transecto & $\begin{array}{l}\text { Monroy-Ortiz, } \\
2010\end{array}$ \\
\hline Región del Balsas & Cinco & 0.62 & Sin aprovechamiento & Transecto & $\begin{array}{c}\text { Maldonado et al., } \\
2013\end{array}$ \\
\hline Guerrero & $\begin{array}{l}\text { Cuatro adultos y } \\
\text { tres juveniles }\end{array}$ & $7.6^{*}$ & $\begin{array}{l}\text { Recolección de especies } \\
\text { medicinales. }\end{array}$ & $\begin{array}{l}\text { Cuadrante centrado } \\
\text { en un punto }\end{array}$ & $\begin{array}{l}\text { Datos propios, } \\
2012\end{array}$ \\
\hline
\end{tabular}




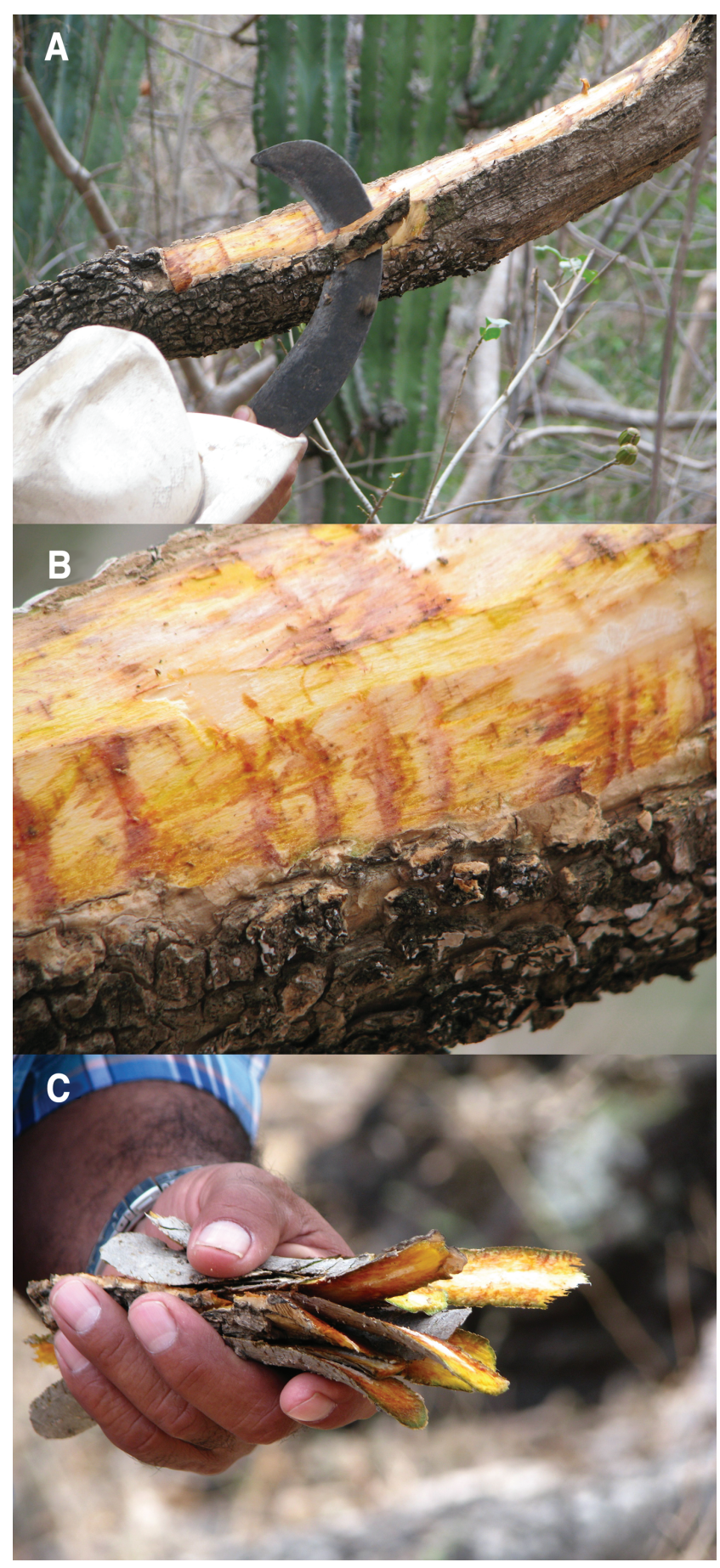

Figura 5. Cosecha de Hintonia latiflora: A) descortezamiento, B) exposición del ritidoma y la peridermis, C) corteza cosechada.

$>9 \mathrm{~cm}$ de diámetro basal (DB), grosor de corteza de $0.9 \mathrm{~cm}$ y cobertura $\approx 5 \mathrm{~m}$. Los mayores DB observados fueron de $20 \mathrm{~cm}$. En contraste, individuos con porte arbustivo tienen menos segmentos por rama, $4 \mathrm{~cm}$ de $\mathrm{DB}$, con un grosor de corteza de $0.2 \mathrm{~cm}$ y cobertura de $6.5 \mathrm{~m}$. Las estimaciones, producto de entrevistas en Tlalcozotitlán, indican que 100 familias recolectoras cosechaban aproximadamente 20 to-
Cuadro 2. Producción de corteza de Hintonia latiflora. *Este parámetro se basa en la percepción de los recolectores sobre la disponibilidad espacial de Hintonia latiflora en Tlalcozotitlán.

\begin{tabular}{lcccc}
\hline $\begin{array}{l}\text { Estadio } \\
\text { de } \\
\text { desarrollo }\end{array}$ & Diámetro & $\begin{array}{c}\text { Producción } \\
\text { basal }(\mathrm{cm})\end{array}$ & $\begin{array}{c}\text { Abundancia* } \\
\text { de corteza } \\
\text { (peso seco) }\end{array}$ & Fuente \\
\hline Adulto & 39 & $3.8 \mathrm{~kg}$ & Escasa & $\begin{array}{c}\text { Descortezamiento } \\
\text { de un individuo }\end{array}$ \\
Juvenil & $<20$ & $500 \mathrm{~g}$ & Abundante & $\begin{array}{c}\text { Entrevistas a } \\
\text { recolectores }\end{array}$ \\
\hline
\end{tabular}

neladas semanales de corteza de Hintonia latiflora en los años 90.

La principal región que ha abastecido al mercado nacional e internacional de corteza de Hintonia latiflora es la Depresión del Balsas, México, que incluye a los estados de Guerrero, Morelos y Puebla (Hersch-Martínez, 1996; Hersch-Martínez y Fierro, 2001). También en los estados de Chihuahua y Aguascalientes se comercializa la quina amarilla (Bye, 1986; CONABIO, 2008), y aparece en otros mercados del país, aun cuando esas regiones no sean productoras de corteza. La cadena de mercado de la quina en Tlalcozotitlán está conformada por tres actores: los recolectores, los acopiadores locales y los compradores regionales; estos últimos son los distribuidores.

Los precios históricos de la corteza al consumidor han aumentado, de \$13 pesos (moneda nacional) en 1989 a \$57 pesos por kg en 2011 (Figura 6A). Pero en términos reales (con el efecto de la inflación), se observa una fuerte baja de los precios entre aquellos mencionados para el inicio de los 90 y los de 2011, de $\$ 169$ pesos por kg a $\$ 62$ pesos (Figura 6B). En Tlalcozotitlán, que es el sitio de recolección (ahora regulado), un kilo de corteza de Hintonia latiflora es comprado a los recolectores en $\$ 20$ pesos. Un kilogramo se vende al consumidor, en el Mercado de Sonora del Distrito Federal, en $\$ 57$ pesos.

\section{Discusión}

A la fecha (2014), no existe unanimidad en las fuentes taxonómicas acerca de la aceptación de los taxa propuestos por Bullock y la delimitación de Hintonia latiflora. OchoterenaBooth (2000) apunta a un solo taxón con amplia variación morfológica en su área de distribución, lo que es consistente con lo señalado por Lorence y Taylor (2012).

Los resultados de esta investigación fueron diferentes con algunos elementos de la morfología conocida de la especie. Ochoterena-Booth (2000) describe árboles de $10 \mathrm{~m}$ de altura, pero en Tlalcozotitlán, los árboles adultos solo alcanzan $3.5 \mathrm{~m}$ y tienen copas muy amplias, de alrededor de $5 \mathrm{~m}$ de diámetro. También describe a las flores como axilares, mientras que en los ejemplares observados en campo y de herbario tienen flores axilares y apicales. Otra diferencia fue la heterostilia, este carácter estuvo ausente en las po- 

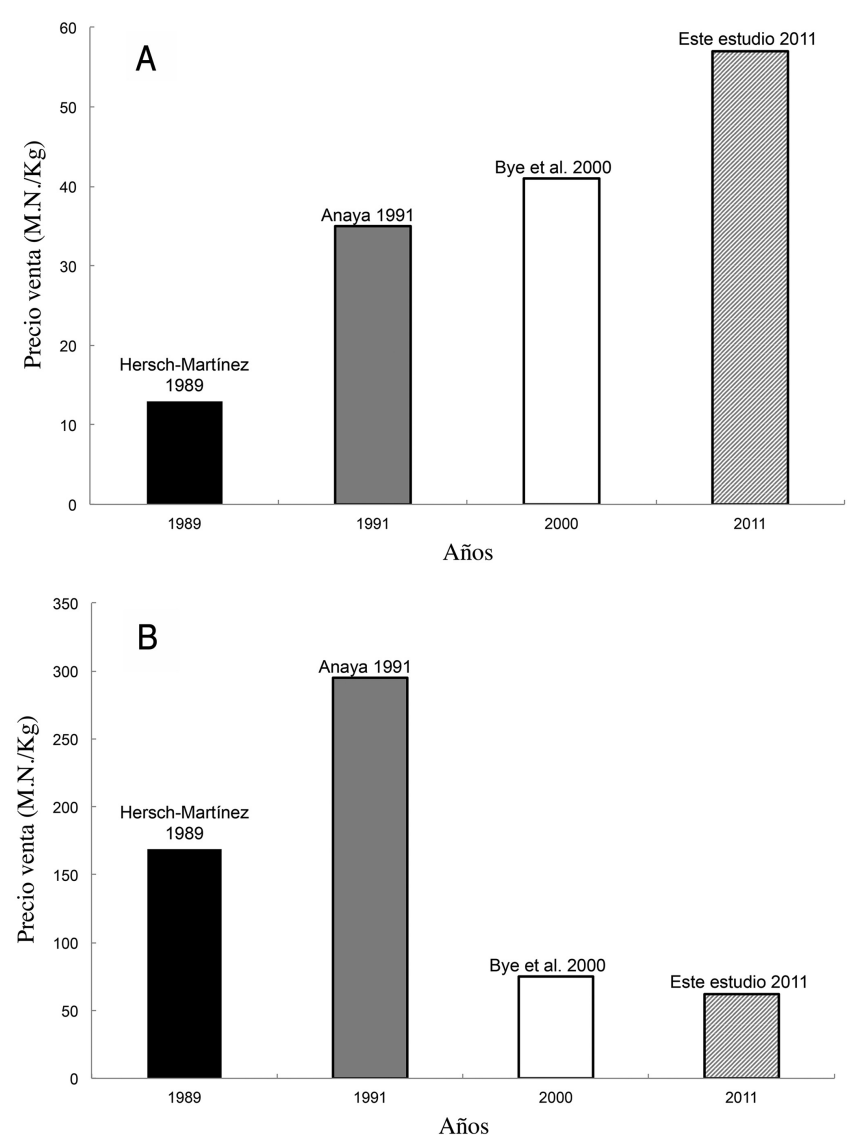

Figura 6. Precio de venta (pesos mexicanos) de Hintonia latiflora en diferentes mercados de México, en las últimas dos décadas. A) Valores promedio a partir de los autores citados. B) Precios reales, considerando la inflación. Los porcentajes de inflación fueron 1,200\% para 1989 a 2013 (Hersch-Martínez, 1996); 744\% (AnayaDávila Garibi, 1991); 84\% (Bye et al., 2000) y 10\% (datos de este estudio, 2011).

blaciones de Tlalcozotitlán. Se desconoce la variabilidad o polimorfismo que pudiera tener la especie. Dada la amplia distribución de la quina amarilla en diversas provincias biogeográficas, es probable que la altura baja, el dosel amplio y la limitación del crecimiento mediante inflorescencias apicales, sean las respuestas de los individuos a las condiciones restrictivas del medio donde se desarrollan las poblaciones observadas: seco, caluroso, suelos someros, pedregosos e inclinados preferentemente, ya sea en laderas o cañadas y esporádicamente en planicies.

Por lo general, las características del hábitat de Tlalcozotitlán coinciden con las de sitios mencionados en la literatura, bosque tropical caducifolio y matorral xerófilo, en sitios conservados y perturbados, en sitios soleados y además, en sombreados. No se confirma que la quina amarilla sea estrictamente heliófita (Huante et al., 1995; López et al., 2011). Es muy probable que para la etapa de establecimiento sí sea importante la sombra proporcionada por la planta madre y las plantas vecinas, lo que es un probable caso de nodrizaje, y que con el paso del tiempo y el crecimiento de las plantas, las pequeñas logren sobrepasar en la etapa adulta, al dosel que inicialmente les protegió, dando la apariencia que han sido totalmente heliófitas. De hecho, las plantas que crecen bajo la sombra de otras, crecen delgadas y, antes de estar suprimidas por la interferencia de luz, ellas tienden a modificar sus tallos para orientarlos hacia los sitios más soleados.

Hintonia latiflora, actualmente, tiene baja densidad poblacional, de algunos pocos individuos por hectárea, lo que limita la posibilidad de que la zona se regenere pronto con esta especie de manera natural y, por supuesto, la baja densidad también reduce las posibilidades de obtener una cosecha abundante, sostenida y exportable como en otros tiempos.

La fenología vegetativa y reproductiva de Hintonia latiflora mostró diferenciación temporal. Mientras que se indica sincronía de floración y foliación en Jalisco (Bullock y Solís-Magallanes, 1990), en nuestras observaciones en Guerrero hubo un desfasamiento claro; primero ocurre la floración, luego la foliación, y con el transcurso del tiempo, la fructificación; es probable que esta asincronía entre eventos vegetativos y reproductivos corresponda con lo limitado de los recursos, y que se dé prioridad a la reproducción aprovechando las escasas lluvias dejadas por los frentes fríos del periodo invernal. El desarrollo vegetativo post-fertilización y la fructificación se fortalecen con las lluvias de verano.

La dispersión no solo es anemócora, como se señala en la literatura, sino también tiene características barócoras, ya que las semillas pueden caer agrupadas por falta de apertura del fruto. En parte, es ventajoso este método porque las semillas quedan bajo el dosel materno y como se protegen bajo la sombra, el beneficio sería emerger con un microclima más favorable.

La viabilidad y potencial germinativo de las semillas de Hintonia latiflora es alta porque carecen de latencia, pero fuera de lo publicado por la Seed Information Database (2013), no existen estudios en condiciones de campo ni de invernadero en torno a la germinación. La propagación asexual hasta ahora, no ha sido una alternativa exitosa para la multiplicación de esta especie.

La descripción taxonómica de la especie no distingue morfotipos. En este estudio se identificaron dos morfotipos de Hintonia latiflora, descritos con base en el modelo arquitectónico Leeuwenberg descrito por Hallé et al. (1978) y reiterado por Hallé (2010), debido a que las ramas son bifurcadas, ortotrópicas y las flores son apicales, además de axilares. Los individuos adultos y juveniles tienen ramificación mesótona, pero hay varios juveniles que tienen ramificación basítona, plagio-ortotrópica y porte arbustivo, y como detalle común, resalta que crecen y desarrollan en sitios con intenso disturbio, inclusive, forman matorrales. Se considera que las modificaciones arquitectónicas de este morfotipo pudieran atribuirse tanto al ambiente como al grado de alteración del sitio, originado del ramoneo por cabras y el derribo de individuos desde la base para el aprovechamiento de la corteza, de manera que las multirrami- 
ficaciones, en realidad, corresponderían con reiteraciones del modelo original, ya que no se pierde la bifurcación que identifica al tronco en el modelo arquitectónico. La arquitectura de $H$. latiflora es de utilidad para comprender el volumen de corteza que un recolector puede obtener de individuos con diferente morfotipo.

Los principales usos de la quina amarilla (como febrífugo asociado con el paludismo y como antidiabético), se sustentan en resultados experimentales, que incluyen algunos datos clínicos y el conocimiento de sus componentes químicos (Mata et al., 2009). Pero además de ser un producto medicinal, la quina amarilla tiene otros usos; se ha evaluado el empleo de sus ramas como sostén o espalderas de cultivos en Sonora, México (Rendón-Carmona et al., 2009), y se menciona en una etiqueta de herbario (Pennington 26 [TEX]) el uso de la corteza como incienso en el mismo estado, aunque no se considera planta aromática en el área de estudio. El tallo se utiliza para la construcción de cercos vivos en Sinaloa (Ochoterena-Booth, 2000), y en Tlalcozotitlán la madera se aprovecha para construcción y leña.

En lo que respecta al manejo de la corteza, el ritidoma se cae de manera natural durante el proceso de recolección y en el manejo post-cosecha (transporte y deshidratado). La corteza interna (felodermis, floema secundario y cámbium vascular), y en ocasiones hasta el albura (xilema funcional), son la parte aprovechada como medicinal. El problema de cosechar hasta la corteza interna es que se interrumpe el funcionamiento de floema y xilema y, por consecuencia, muere el árbol.

Desde que inició la recolecta, por los años 20 del siglo pasado (Hersch-Martínez, 2007), la recolección de corteza siempre ha sido excesiva, situación que concuerda con las respuestas de los entrevistados. Las poblaciones de porte arbóreo de Hintonia latiflora antes colindaban con Tlalcozotitlán, actualmente se encuentran distantes (a $9.5 \mathrm{~km}, 4.5 \pm$ 1 hora caminando) y su densidad es baja. Pero aún en sitios alejados, solo se encuentran árboles relativamente pequeños con un DB de hasta $20 \mathrm{~cm}$, los árboles de talla grande ( $\geq 30 \mathrm{~cm}$ de diámetro) son escasos, ya que la mayoría se cosechó hace unos 20 años; se puede inferir que el mejoramiento de la infraestructura carretera en el área de estudio, a finales de los años 1990's, también promovió el derribo de árboles y la disminución de las poblaciones de quina.

En cuestión económica, el margen de ganancia de los intermediarios parece alto, ya que los recolectores únicamente reciben una tercera parte del precio de venta; sin embargo, este margen es relativamente normal para productos agropecuarios (Mendoza, 1995) y otras especies medicinales (Hersch-Martínez, 1996).

La problemática generada por la intermediación, la dinámica de la demanda nacional e internacional y la situación marginal de las familias recolectoras, indujo a recolectar quina amarilla intensivamente a partir de los años 80 del siglo pasado. Esto parece ser un patrón para la flora medici- nal en México (Hersch-Martínez, 1996; Hersch-Martínez y Fierro, 2001). La confluencia de los atributos biofísicos y la cadena de comercialización han generado que, actualmente, Hintonia latiflora se encuentre amenazada en algunas zonas de su área de distribución (Barrance et al., 2009), particularmente en la Cuenca del Alto Balsas, México.

Para que funcione la gestión sostenible, se requiere mayor conocimiento de la especie, regulación y vigilancia del acceso al recurso. En México, la NOM-005-RECNAT-1997, actualmente Proyecto de Norma Oficial Mexicana NOM005-SEMARNAT-2012 (SEMARNAT, 2012), es la única medida legal que establece los criterios para la gestión de recursos forestales no maderables, como Hintonia latiflora. En Tlalcozotitlán, desde hace aproximadamente diez años, se encuentra formalmente prohibida la recolecta comercial de quina amarilla, por acuerdo entre autoridades comunales y los representantes de la Comisión Nacional Forestal. Este acuerdo consiste en conservar a las especies forestales en la comunidad a cambio de que les sean aprobados proyectos productivos y pagos por servicios ambientales. Debido a la baja del precio relativo de H. latiflora, la regulación impuesta, la escasez del recurso y el cambio en los factores socioeconómicos y culturales de la región, se ha reducido la presión de cosecha de corteza. En opinión de algunos recolectores, existe una ligera recuperación de las poblaciones de H. latiflora.

\section{Conclusiones}

Hintonia latiflora, la quina amarilla, es una especie medicinal originaria del trópico seco mexicano, cuyas poblaciones silvestres fueron sobrecosechadas en el siglo pasado, al punto en que actualmente están notablemente disminuidas en su densidad y tamaño; además, han modificado su forma. Existen dos morfotipos, el original modelo arquitectónico Leeuwenberg: mesótono, dicotómico, ortotrópico y de floración axilar-terminal; y otro, que sigue el mismo modelo pero es propiamente reiterado: arbusto basítono, de ramas plagio-ortotrópicas, con características del modelo original, dicotomías por orden de ramificación y floración principalmente apical. Esta revisión indica que los factores biofísicos y ecológicos limitantes más importantes para el establecimiento, crecimiento y supervivencia de H. latiflora, son el suelo somero y pedregoso y la presencia de plantas nodriza. La especie tiene una densidad baja, lo que anticipa que no puede ser sujeta a un aprovechamiento forestal intensivo. La recolección de $H$. latiflora actualmente es regulada localmente para asegurar la conservación.

El proceso de cosecha-comercialización ha implicado a toda una cadena de producción, inclusive a escala de exportación, pero en la actualidad hay intervención de la vigilancia y normatividad impuesta por acuerdo entre la sociedad y el gobierno mexicano. 


\section{Agradecimientos}

Los autores agradecen a la población y autoridades del Núcleo Agrario de Tlalcozotitlán por el apoyo e información proporcionados para este documento. El primer autor agradece el financiamiento otorgado (becario 265032) por el Consejo Nacional de Ciencia y Tecnología (CONACYT) y, al Colegio de Postgraduados por los recursos destinados al trabajo de campo. Se agradece también a los curadores de los Herbarios CHAPA, HUMO, IEB y MEXU por las facilidades para la consulta de especímenes de Hintonia latiflora y, al dibujante Juan Antonio Rodríguez-Salgado por la realización de la Figura 4. Finalmente, se agradece a los revisores anónimos del documento, quienes con sus comentarios colaboraron para la mejora de la presente contribución.

\section{Literatura citada}

Aiello A. 1979. A reexamination of Portlandia (Rubiaceae) and associated taxa. Journal of the Arnold Arboretum 60:38-126.

Alonso-Castro A.J., Villarreal M.L., Salazar-Olivo L.A., GómezSánchez M., Domínguez F. y García-Carranca A. 2011. Mexican medicinal plants used for cancer treatment: Pharmacological, phytochemical and ethnobotanical studies. Journal of Ethnopharmacology 133:945-972.

Álvarez-Yépiz J.C., Martínez-Yrízar A., Búrquez A. y Lindquist C. 2008. Variation in vegetation structure and soil properties related to land use history of old-growth and secondary tropical dry forests in northwestern Mexico. Forest Ecology and Management 256:355-366.

Anaya-Dávila Garibi M. 1991. Estudio etnobotánico del complejo Quina en México. Tesis de Licenciatura, Facultad de Ciencias, Universidad Nacional Autónoma de México, México, D.F. 164 pp.

Argotte-Ramos R., Ramírez-Ávila G., Rodríguez-Gutiérrez M.C., Ovilla-Muñoz M., Lanz-Mendoza H., Rodríguez M.H., González-Cortazar M. y Álvarez L. 2006. Antimalarial 4-phenylcoumarins from the stem bark of Hintonia latiflora. Journal of Natural Products 69:1442-1444.

Arredondo-Amezcua L. 2010. Espectro de dispersión de la flora leñosa de la estación de biología Chamela, Jalisco, México. Tesis de Maestría, Centro de Investigaciones en Ecosistemas, Universidad Nacional Autónoma de México, Morelia. 103 pp.

Barrance A., Schreckenberg K. y Gordon J. 2009. Conservación Mediante el Uso: Lecciones Aprendidas en el Bosque Seco Tropical Mesoamericano. Overseas Development Institute, Londres.

Beltrán-Rodríguez L.A. 2013. Estructura morfológica-poblacional de Hintonia latiflora (Rubiaceae) relacionada con el descortezamiento, en la Cuenca Alta del Balsas México. Tesis de Maestría, Colegio de Postgraduados, Montecillo. 168 pp.

BDMTM. Biblioteca Digital de la Medicina Tradicional Mexicana. 2009. Universidad Nacional Autónoma de México. <www. medicinatradicionalmexicana.unam.mx/monografia.php?l=3\&t =Copalquín\&id=7361> (consultado 11 agosto 2013).

Borhidi A. 2006. Rubiáceas de México. Akadémiai Kiadó, Budapest.

Bullock A. 1935. Hintonia latiflora var. leiantha. Hooker's Icones Plantarum 33:tabula 3295.

Bullock S.H. y Solís-Magallanes J.A. 1990. Phenology of canopy trees of a tropical deciduous forest in Mexico. Biotropica 22:22-35.
Bye R.A. 1986. Medicinal plants of the Sierra Madre: Comparative study of Tarahumara and Mexican market plants. Economic Botany 40:103-124.

Bye R, Mendoza M., Morales G., Hilerio M., Rodríguez J., Toledo G., Linares E., Herrera E y Timmermann B. 2000. Convenio sobre la diversidad biológica y la conservación en la selva baja caducifolia en México: una experiencia. En: Monroy R., Colín H. y Boyas D.J.C. Eds. Los Sistemas Agroforestales de Latinoamérica y la Selva Baja Caducifolia en México, pp. 233251, Instituto de Investigaciones para la Cooperación Agrícola, Instituto de Investigaciones Forestales, Agrícolas y Pecuarias, Universidad Autónoma del estado de Morelos, Cuernavaca.

Camacho-Corona M.R. 1990. Nuevos metabolitos secundarios de Hintonia latiflora (Sessé \& Moc. ex DC.) Bullock, y aislamiento de compuestos bioactivos del Teloxys graveolens (Willd.) W.A. Weber. Tesis de Maestría en Ciencias Químicas, Universidad Nacional Autónoma de México, México, D.F. 205 pp.

Castañeda-Huitrón A.L. 2010. Métodos de propagación de la planta medicinal copalche Hintonia latiflora. Tesis de Licenciatura, Facultad de Ciencias, Universidad Nacional Autónoma de México, México, D.F. 95 pp.

CONABIO. Comisión Nacional para el Conocimiento y Uso de la Biodiversidad. 2008. La Biodiversidad en Aguascalientes: Estudio de Estado. Comisión Nacional para el Conocimiento y Uso de la Biodiversidad, Instituto del Medio Ambiente del Estado de Aguascalientes, Universidad Autónoma de Aguascalientes, México, D.F.

Cristians S., Bye R., Navarrete A. y Mata R. 2013. Gastroprotective effect of Hintonia latiflora and Hintonia standleyana aqueous extracts and compounds. Journal of Ethnopharmacology 145:530-535.

Cristians S., Guerrero-Analco J.A., Pérez-Vásquez A., PalaciosEspinosa F., Ciangherotti C., Bye R. y Mata R. 2009. Hypoglycemic activity of extracts and compounds from the leaves of Hintonia standleyana and H. latiflora: Potential alternatives to the use of the stem bark of these species. Journal of Natural Products 72:408-413.

Déciga-Campos M., Rivero-Cruz I., Arriaga-Alba M., Castañeda-Corral G., Angeles-López G.E., Navarrete A. y Mata R. 2007. Acute toxicity and mutagenic activity of Mexican plants used in traditional medicine. Journal of Ethnopharmacology 110:334-342.

Delprete P.G. 2004. Rubiaceae. En: Smith N.P., Heald S.V., Henderson A., Mori S.A. y Stevenson D.W. Eds. Flowering Plant Families of the American Tropics, pp. 328-333, New York Botanical Garden Press, Princeton University Press, Nueva York.

Fierro A.A., Guerrero C.J., Hersch-Martínez P. y Pérez C.A. 2000. Seis especies medicinales silvestres cuya corteza presenta importancia medicinal, provenientes de la selva baja caducifolia: algunas condiciones para su propagación. En: Monroy R., Colín H. y Boyas D.J.C. Eds. Los Sistemas Agroforestales de Latinoamérica y la Selva Baja Caducifolia en México, pp. 543550, Instituto de Investigaciones para la Cooperación Agrícola, Instituto de Investigaciones Forestales, Agrícolas y Pecuarias, Universidad Autónoma del Estado de Morelos, Cuernavaca.

Gavito M.E., Pérez-Castillo D., González-Monterrubio C.F., Vieyra-Hernández T. y Martínez-Trujillo M. 2008. High compatibility between arbuscular mycorrhizal fungal communities and seedlings of different land use types in a tropical dry ecosystem. Mycorrhiza 19:47-60.

Gross G.G. 2008. From lignin to tannins: Forty years of enzyme 
studies on the biosynthesis of phenolic compounds. Phytochemistry 69:3018-3031.

Harborne J.B. 1993. The Flavonoids: Advances in Research Since 1986. Chapman \& Hall, Londres.

Hallé F. 2010. Arquitectura de los árboles. Boletín de la Sociedad Argentina de Botánica 45:405-418.

Hallé F., Oldeman R.A.A. y Tomlison P.B. 1978. Tropical Trees and Forests: An Architectural Analysis. Springer-Verlag, Berlín.

Hersch-Martínez P. 1996. Destino Común: Los Recolectores y su Flora Medicinal. El Comercio de Flora Medicinal Silvestre desde el Suroccidente Poblano. Instituto Nacional de Antropología e Historia, México, D.F.

Hersch-Martínez P. 2007. La industrialización químico-farmacéutica mexicana y la flora: el caso de los Laboratorios Garcol. Boletín de la Sociedad Química de México 1:107-114.

Hersch-Martínez P. y Fierro A. 2001. El comercio de plantas medicinales: algunos rasgos significativos en el centro de México. En: Rendón B., Rebollar S., Caballero J. y Martínez-Alfaro, M. Eds. Plantas, Cultura y Sociedad. Estudio sobre la Relación entre los Seres Humanos y las Plantas de los Albores del Siglo XXI, pp.5375, UAM-Iztapalapa y Secretaría de Agricultura, Ganadería, Desarrollo Rural, Pesca y Alimentación. México, D.F.

Hernández-Pérez V. 2006. Reservas en semillas y su papel en las primeras etapas de desarrollo de especies leñosas de selva baja caducifolia. Tesis de Maestría, Instituto de Biología, Universidad Nacional Autónoma de México. México, D.F. 112 pp.

Huante P., Rincón E. y Acosta I. 1995. Nutrient availability and growth rate of 34 woody species from a tropical deciduous forest in Mexico. Functional Ecology 9:849-858.

Huante P., Ceccon E., Orozco-Segovia A., Sánchez-Coronado M.E., Acosta I. y Rincón E. 2012. The role of arbuscular mycorrhizal fungi on the early stage restoration of seasonally dry tropical forest in Chamela, Mexico. Revista Árvore, Viçosa-MG 36:279-289.

Kiehn M. 1995. Chromosome survey of the Rubiaceae. Annals of the Missouri Botanical Garden 82:398-408.

Lawrence D. 2003. The response of tropical tree seedlings to nutrient supply: meta-analysis for understanding a changing tropical landscape. Journal of Tropical Ecology 19:239-250.

Lorence D.H. y Taylor C.M. 2012. Rubiaceae. Flora Mesoamericana 4:230-232.

López V.R., Cházaro B.M., González M.R.M. y Covarrubias L.H. 2011. Árboles de las Barrancas de los ríos Santiago y Verde. Gobierno de Jalisco, Comisión Estatal del Agua de Jalisco, Guadalajara.

Maldonado B., Caballero J., Delgado-Salinas A. y Lira R. 2013. Relationship between use value and ecological importance of floristic resources of seasonally dry tropical forest in the Balsas River Basin, Mexico. Economic Botany 67:17-29.

Manss U. y Bremer B. 2010. Towards a better understanding of intertribal relationships and stable tribal delimitations within Cinchonoideae s.s. (Rubiaceae). Molecular Phylogenetics and Evolution 56:21-39.

Mata R., Navarrete A., Cristians S., Hersch P. y Bye R. 2009. Plantas Medicinales de México. Monografía Científica. Pruebas de Control de Calidad (Identificación y Composición), Eficacia y Se- guridad. Copalchi - Hintonia latiflora (Sessé et Mociño ex DC.) Bullock (Rubiaceae). Sentido Giratorio Ediciones, México, D.F.

Mendoza G. 1995. Compendio de Mercadeo de Productos Agropecuarios. $2^{\mathrm{a}}$ ed. Instituto Interamericano de Cooperación para la Agricultura, San José.

Monroy-Ortiz C. 2010. Conocimiento ecológico tradicional para la gestión sostenible de especies forestales no maderables. Tesis Doctoral, Colegio de Postgraduados, Montecillo. 119 pp.

Monroy-Ortiz C., García-Moya E., Romero-Manzanares A., Sánchez-Quintanar C., Luna-Cavazos M., Uscanga-Mortera E., Flores-Guido J.S. y González-Romero V. 2013. Plants of local interest for medicinal and conservation purposes in Morelos, Mexico. Studies on Ethno-Medicine 7:13-26.

Motley T.J., Wurdack K.J. y Delprete P.G. 2005. Molecular systematics of the Catesbaeeae-Chiococceae complex (Rubiaceae): Flower and fruit evolution and biogeographic implications. American Journal of Botany 92:316-329.

Ocampo R.A. 1994. Domesticación de plantas medicinales en Centroamérica. Informe técnico $\mathrm{N}^{0} 245$. Centro Agronómico Tropical de Investigación y Enseñanza, Turrialba.

Ochoterena-Booth H. 2000. Systematics of Hintonia Bullock and the Portlandia complex (Rubiaceae). Tesis Doctoral, Cornell University, Nueva York. 306 pp.

Rendón-Carmona H., Martínez-Yrízar A., Balvanera P. y PérezSalicrup D. 2009. Selective cutting of woody species in a Mexican tropical dry forest: Incompatibility between use and conservation. Forest Ecology and Management 257:567-579.

Romero-Duque L.P., Jaramillo V.J. y Pérez-Jiménez A. 2007. Structure and diversity of secondary tropical dry forests in Mexico, differing in their prior land-use history. Forest Ecology and Management 253:38-47.

SEMARNAT. Secretaría de Medio Ambiente y Recursos Naturales. 2012. Proyecto de Norma Oficial Mexicana PROY-NOM005-SEMARNAT-2012 Que establece los criterios para realizar el aprovechamiento sustentable de los recursos forestales no maderables existentes en los ecosistemas forestales; bosques de clima templado frío, selvas y zonas áridas y semiáridas-Especificaciones técnicas.

Seed Information Database. 2013. Hintonia latiflora. RBG Kew, Wakehurst Place. <http://data.kew.org/sid/SidServlet?Clade $=\&$ Order $=\&$ Family $=\& A P G=$ off $\&$ Genus $=$ Hintonia $\&$ Species $=$ latifl ora\&StorBehav $=0>$ (consultado 15 mayo 2013).

Soriano D., Orozco-Segovia A., Márquez-Guzmán J., Kitajima K., Gamboa-de Buen A. y Huante P. 2011. Seed reserve composition in 19 tree species of a tropical deciduous forest in Mexico and its relationship to seed germination and seedling growth. Annals of Botany 107:939-951.

Standley P.C. y Williams L.O. 1975. Rubiaceae. Flora of Guatemala Part XI, Number 1 a 3. Fieldiana 24:97-98.

Stranczinger S., Szentpéteri J.L. y Borhidi A. 2006. Sequence differentiation between some DNA regions of Hintonia latiflora and Hintonia standleyana. Acta Botanica Hungarica 48:435-440.

Vargas-Rodríguez Y.L., Vázquez-García J.A. y Williamson G.B. 2005. Environmental correlates of tree and seedling-sapling distributions in a Mexican tropical dry forest. Plant Ecology 180: 117-134.

Recibido: 15 de noviembre de 2013

Aceptado: 5 de abril de 2014 